\title{
Controvérsia entre Lei Complementar e Lei Ordinária: um estudo com base na anômala técnica legislativa do art. 86 do Estatuto Nacional da Microempresa e Empresa de Pequeno Porte
}

Irene Patrícia Nohara'

\section{Introdução da problemática}

Apesar de ser um dos temas básicos de Direito, a diferenciação entre lei complementar e lei ordinária ainda é um dos assuntos que mais provocam polêmicas tanto na doutrina como na jurisprudência.

Os manuais de Direito Constitucional, via de regra, ${ }^{2}$ apenas apontam a diferenciação entre as duas espécies normativas a partir da descrição do fato de que existem na Constituição matérias reservadas às leis complementares, que são aprovadas por um quorum diferenciado daquele exigido para votação de projetos de leis ordinárias, especificando seus posicionamentos acerca da presença ou não de hierarquia entre elas.

Assim, se um projeto de lei complementar for sancionado sem que tenha atingido na votação o quorum de maioria absoluta, ocorre patente vício formal de inconstitucionalidade que tem o potencial de provocar um controle cuja conseqüência é a declaração de inconstitucionalidade da lei como um todo.

Todavia, muito embora alguns casos sejam singelos e de incontroversa interpretação - como, por exemplo, a necessidade de lei complementar para a criação de regiōes metropolitanas, conforme exigência contida no art. $25, \mathbb{\$} 3^{\circ}$, da Constituição Federal -, outros dispositivos constitucionais não dão ao intérprete tanta

Doutora e Mestre em Direito do Estado pela Faculdade de Direito da Universidade de São Paulo.

2 Cf. SILVA, José Afonso da. Curso de direito constitucional positivo. 18. ed. São Paulo: Malheiros, 2000. p. 533. FERREIRA FILHO, Manoel Gonçalves. Curso de direito constitucional. São Paulo: Saraiva, 2002. p. 208. TEMER, Michel. Elementos de direito constitucional. Sāo Paulo: Malheiros, 2002. p. 146. 
certeza sobre a sua abrangência e provocam divergências entre doutrinadores e os próprios parlamentares, como ocorre com o art. 146, III, da Constituição, que determina que cabe à lei complementar estabelecer "normas gerais" em matéria tributária, ${ }^{3}$ especialmente sobre os itens listados em suas alíneas, entre as quais destacamos a definição de tratamento diferenciado e favorecido para as microempresas e empresas de pequeno porte (alínea $d$ ).

Norma geral é expressão que contempla conceito indeterminado, isto é, termo cuja extensão significativa não é precisa. Assim, enquanto alguns intérpretes dirão que algo é assunto que se encaixa perfeitamente numa norma geral, pode ser que de outros pontos de vista o mesmo assunto seja enfocado como particularismo, isto é, como minúcia que não possui generalidade; sem falar nos casos em que o legislador quer aproveitar a oportunidade e regular em lei complementar todos os assuntos pertinentes à matéria discutida, como ocorreu no novo Estatuto da Microempresa e da Empresa de Pequeno Porte, para o qual, em virtude da Reforma Tributária que culminou na Emenda 42/03, o Poder Reformador exigiu que o tratamento diferenciado e favorecido fosse objeto de lei complementar e, na discussão do projeto de lei, os parlamentares aproveitaram a oportunidade para criar um regramento único, evitando, por conseguinte, a dispersão legislativa.

Entretanto, tal escolha acabou por incluir no âmbito da Lei Complementar $\mathrm{n}^{\circ}$ 123/06 assuntos que eram passíveis de aprovação por lei ordinária, como as alteraçōes de favorecimento no âmbito das compras governamentais, isto é, processadas na Lei de Licitaçōes. Antevendo as dificuldades que esta opção produziria, os próprios legisladores criaram um artigo de técnica legislativa absolutamente anômala que é extremamente fecundo para o aprofundamento da discussão da natureza jurídica da lei complementar, in verbis: "Art. 86. As matérias tratadas nesta Lei Complementar que não sejam reservadas constitucionalmente a lei complementar poderão ser objeto de alteração por lei ordinária."

O art. 86 é um exemplo de técnica legislativa anômala, pois, apesar de o dispositivo em comento representar a incorporação de uma tendência jurisprudencial que se firmava paulatinamente no Supremo Tribunal Federal, entendemos que o legislador infraconstitucional não deveria tê-la enunciado como regra jurídica, admitindo, portanto, que optou por tramitar em projeto de lei complementar matéria absolutamente alheia à matéria reservada pela Constituição para a espécie normativa.

\section{Natureza jurídica e hierarquia}

Tanto a lei complementar como a lei ordinária são espécies normativas primárias enunciadas no art. 59 da Constituição Federal. Na realidade, o texto cons-

\footnotetext{
3 Observe-se que o grande número de assuntos que exigem lei complementar no âmbito do Direito Tributário e que causam discuissōes nos tribunais fez com que se encontre com mais facilidade trabalhos que aprofundam tal abordagem na área tributária do que nas demais áreas do Direito.
} 
titucional pouco diz acerca da lei complementar e quase nenhuma pista fornece sobre sua relação com a lei ordinária, de modo que a discussão da presença ou não de hierarquia entre essas duas espécies legislativas apóia-se inteiramente nos estudos doutrinários.

Autores que defendem que as leis complementares ocupam um espaço privilegiado em relação às leis ordinárias no ordenamento baseiam-se no excerto da obra de Miguel Reale, que considera as primeiras "um tertium genus de leis, que não ostentam a rigidez dos preceitos constitucionais, nem tampouco devem comportar revogação (perda da vigência) por força de qualquer lei ordinária superveniente". ${ }^{4}$

A partir do desenvolvimento deste raciocínio, considera Alexandre de Moraes que a idéia de lei complementar foi inspirada no fato de que o legislador constituinte pretendeu "resguardar determinadas matérias de caráter infraconstitucional contra alterações volúveis e constantes, sem, porém, lhes exigir a rigidez que impedisse a modificação de seu tratamento, assim que necessário". ${ }^{5}$

Filia-se, pois, o autor à corrente que propaga a existência de hierarquia entre leis complementares e leis ordinárias. Este posicionamento doutrinário é capitaneado por Manoel Gonçalves Ferreira Filho, cujo argumento central é extraído do seguinte trecho do clássico Curso de direito constitucional:

É de se sustentar que a lei complementar é um tertium genus interposto, na hierarquia dos atos normativos, entre a lei ordinária e a Constituição. Tal é o entendimento de Pontes de Miranda nos seus Comentários à Constituição de 1967. Não é só, porém, o argumento de autoridade que apóia essa tese; a própria lógica jurídica o faz. A lei complementar só pode ser aprovada por maioria qualificada, maioria absoluta, para que nāo seja, nunca, fruto da vontade de uma minoria ocasionalmente em condiçōes de fazer prevalecer sua voz. Essa maioria é um sinal certo da maior ponderação que o constituinte quis ver associada ao seu estabelecimento. Paralelamente, deve-se convir, não quis o constituinte deixar ao sabor de uma decisão ocasional a desconstituição daquilo para cujo estabelecimento exigiu ponderação especial. Aliás, é princípio geral de direito que, ordinariamente, um ato só possa ser desfeito por outro que tenha obedecido à mesma forma. ${ }^{6}$

Assim, pela tese da hierarquia, haveria a prevalência constitucional da lei complementar em relação à lei ordinária pelo fato de que aquela exige o quorum de maioria absoluta. Existe até quem defenda, a partir desta constatação, que a lei ordinária se submete à lei complementar.

4 In: Parlamentarismo brasileiro. São Paulo: Saraiva, 1962. p. 110. Trecho mencionado pelos constitucionalistas: FERREIRA FILHO, Manoel Gonçalves. Curso de direito constitucional. São Paulo: Saraiva, 2002. p. 208 e MORAES, Alexandre de. Direito constitucional. São Paulo: Atlas, 2005. p. 597.

5 Idem, ibidem.

6 FERREIRA FILHO, Manoel Gonçalves. Curso de direito constitucional. São Paulo: Saraiva, 2002. p. 208. 
Michel Temer posiciona-se contrariamente à idéia da hierarquia. Segundo expõe, "hierarquia, para o Direito, é a circunstância de uma norma encontrar sua nascente, sua fonte geradora, seu ser, seu engate lógico, seu fundamento de validade, numa norma superior". ${ }^{7}$ A estrutura escalonada do ordenamento aponta para o fato de que a legislação infraconstitucional é inferior à Constituição porque dela extrai seu fundamento de validade.

A partir desta noção de hierarquia conclui o autor que não é correta a afirmação de que a lei ordinária extrai seu fundamento de validade da lei complementar, pois esta última jamais pode ser considerada fonte geradora ou engate lógico da lei ordinária.

Não há hierarquia entre as duas espécies legislativas tendo em vista que ambas encontram igual fundamento de validade no texto constitucional. Contudo, entendemos que elas se diferenciam quanto ao quorum de aprovação e no que diz respeito ao âmbito material de abrangência, uma vez que o texto constitucional discrimina quais matérias devem ser necessariamente disciplinadas por lei complementar e permite que as demais normas constitucionais não auto-executáveis sejam desdobradas por outras espécies normativas.

Existem, portanto, duas distinções básicas entre as duas espécies: (1) do ponto de vista formal, pois enquanto o quorum de aprovação de leis ordinárias é de maioria simples, as leis complementares são aprovadas por maioria absoluta, conforme determinação contida do art. 69 da Constituição Federal; e (2) do ponto de vista material, pois enquanto existem matérias que a Constituição exige que sejam disciplinadas por meio de leis complementares, as leis ordinárias devem tratar de matérias não reservadas expressamente pela Constituição ao legislador complementar, isto é, o campo material da lei ordinária é, via de regra, residual.

\section{Caminhos interpretativos para solução da invasão da esfera residual pela lei complementar}

Apesar de parcela substancial da doutrina e da jurisprudência defender que o campo material da lei complementar é o taxativamente previsto na Constituição, existem opiniōes divergentes, como aquela de Dagoberto Liberato Cantizano, o qual entende que a enumeração das matérias contidas na Constituição que devem ser reguladas por lei complementar não é exaustiva, pois "nenhum dispositivo expresso existe que impeça a elaboração de outras leis complementares, desde que elas tenham assento em preceito não aplicável e venham a ser aprovadas por maioria absoluta". 8

TEMER, Michel. Elementos de direito constitucional. São Paulo: Malheiros, 2002. p. 146.

8 CANTIZANO, Dagoberto. O processo legislativo nas constituições brasileiras e no direito comparado. Rio de Janeiro: Forense, 1985. p. 227. Apud MORAES, Alexandre. Op. cit. p. 598. 
Também Kiyoshi Harada expõe:

Se é verdade que a Constituição reservou determinadas matérias à disciplina da lei complementar, é verdade também que não vetou a disciplina de qualquer matéria por lei complementar, nem o poderia, pois seria contrário ao bom senso proibir a participação maior dos legisladores, ou seja, não poderia impugnar o excesso de quorum mas apenas a sua falta. ${ }^{9}$

É bastante corrente na discussão sobre o assunto a afirmação de que "quem pode o mais pode o menos", em alusão à possibilidade de uma lei complementar tratar também de assuntos residuais, e não só daqueles escolhidos expressamente pelo Poder Constituinte. Todavia, é importante contra-argumentar que é opção dos parlamentares se determinada matéria será objeto de projeto de lei ordinária ou de projeto de lei complementar, isto é, no processo legislativo não é o simples fato da aprovação de um projeto de lei ordinária por maioria absoluta que o transforma em lei complementar.

Ademais, um dado complicador ressaltado por Alexandre de Moraes $^{10}$ é que determinada matéria reservada ${ }^{11}$ à lei complementar poderá possuir tantas subdivisões que em uma delas poderá acabar confundindo-se com outra matéria residual a ser disciplinada por lei ordinária.

Para solucionar tal impasse, isto é, da situação de o legislador tratar também de matéria de lei ordinária em projeto de lei complementar, abrem-se dois caminhos interpretativos igualmente consistentes, mas que se excluem: o da prevalência do aspecto formal e o da prevalência do aspecto material.

O primeiro deles considera que a lei complementar, conforme mencionado, não se distingue da lei ordinária em função da matéria, mas principalmente do ponto de vista formal. Significa dizer que a forma, isto é, o quorum de votação necessário para a criação e modificação da lei também é aspecto integrante da espécie normativa a ser levado em consideração no momento de sua alteração.

Cumpre, neste ponto, ressaltar que o fato de existir um quorum diferenciado não implica na noção jurídica de hierarquia. Significa, sem dúvida, que aquela matéria foi contemplada por uma opção dos parlamentares no sentido de lhe conferir maior proteção, e isso não pode ser deixado de lado no momento de sua modificação; mas a noção de hierarquia tem relação com o critério de resolução de antinomias jurídicas pelo qual se pressupõe que uma norma localizada em pa-

\footnotetext{
9 HARADA, Kiyoshi. Cofins de profissionais liberais: um novo enfoque. Disponível em: <www.escritorioonline.com/webnews/noticia.php? id_noticia $=6932 \&$ >. Acesso em: 20 fev. 2007.

10 Op. cit. p. 600.

11 Existem, ainda, assuntos tanto reservados como residuais que sāo definidos com conceitos jurídicos indeterminados, como, por exemplo, a noçāo de "normas gerais" que gerou intermináveis disputas doutrinárias e jurisprudenciais seja no âmbito do Direito Tributário, conforme determina o art. 146 da Constituiçāo Federal, que exige lei complementar, ou no âmbito administrativo, em matéria de licitação, de acordo com o art. 22, XXVII, da Lei Maior.
} 
tamar inferior deve obediência à norma hierarquicamente superior na medida em que esta última é seu fundamento de validade (e não por razões cronológicas ou de especialidade).

A teoria escalonada do ordenamento impõe que uma norma localizada em patamar superior seja o fundamento de validade de uma norma infraconstitucional. Contudo, tanto a lei complementar como a lei ordinária têm igualmente sua fonte de engate na Constituição, que está em posição jurídica mais elevada justamente por regular quais são os órgãos e procedimentos de produção jurídica em geral, ou seja, as leis. O que já não mais se aceita, especialmente da formulação kelseniana da pirâmide normativa, é que o fundamento de validade seja critério absolutamente afastado de juízos valorativos, isto é, que a norma de patamar inferior vale como norma jurídica independentemente de seu conteúdo justo ou injusto, pois para Kelsen ${ }^{12}$ todo e qualquer conteúdo pode ser Direito.

Via de regra, não se pode, portanto, dizer que a lei ordinária deve obediência ao conteúdo da lei complementar por motivos hierárquicos; mas isso não significa que o intérprete aceite que lei ordinária possa alterar lei complementar, uma vez que não se pode negar que a lei complementar, por exigir uma vontade qualificada, não deve ser alterada ao sabor das maiorias simples.

\section{Prevalência do aspecto formal}

Quanto à prevalência do aspecto formal, ressalte-se a interessante observação de Hugo de Brito Machado ${ }^{13}$ que, apesar de ter uma opinião distinta da esposada pela autora deste artigo, bem adverte que se ficar a critério de cada doutrinador ou de cada juiz a atribuição de dizer se determinada lej aprovada como lei complementar é realmente dessa espécie normativa, ou se é uma lei ordinária, ocorrerá um desprestígio da segurança jurídica.

A preocupação do autor é correta na medida em que é temerário permitir aos intérpretes autêriticos (isto é, aqueles que têm autoridade para produzir a norrna individual, seja ela sentença ou ato administrativo) a desconstituição indiscriminada da força de leis complementares. Entretanto, é difícil enxergar avanços no dispositivo do art. 86, ainda que do ponto de vista formal, pois achamos que a estranha solução de o legislador conferir expressamente essa possibilidade aos diversos intérpretes de determinada lei complementar representaria reflexamente uma afronta à própria opção legislativa desempenhada.

\footnotetext{
12 KELSEN, Hans. Teoria pura do direito. Coimbra: Arménio Amado, 1984. p. 103.

13 In: Segurança jurídica e a questão da hierarquia da lei complementar. Disponivel em: <www. hugomachado.adv.br $/$ conteudo.asp? home $=1 \&$ secao $=2 \&$ situacao $=2 \&$ doc_id $_{-}=151>$. Acesso em: 21 fev. 2007.
} 


\section{Prevalência do aspecto material}

Identificamo-nos, depois de tortuosas reflexōes, mais com o segundo caminho interpretativo, isto é, com aquele que considera que o aspecto material deve ter prevalência sobre o formal. Apesar de não haver comprovação explícita de que o constituinte quis que somente as matérias reservadas fossem passiveis de tratamento por lei complementar, também não há comprovação inequívoca do raciocínio contrário, isto é, de que, na realidade, ele permitiu que as demais matérias, não reservadas, pudessem ser tratadas por lei complementar. É mais perigoso, ao nosso ver, passar por cima da discriminação material procedida pela Constituição e priorizar a forma, pois essa opção tem o condão de afastar do controle jurisdicional as situações em que o legislador trata por meio de lei complementar de matéria absolutamente alheia aos assuntos reservados.

Imagine-se o caso em que o legislador resolva tratar, por exemplo, de assuntos de Direito Penal por meio de lei complementar. A partir desse momento, diante da priorização da forma, somente se permitirá a alteração daquele assunto por outra lei complementar, ou seja, doravante o assunto nunca mais poderá ser disciplinado por lei ordinária, que supostamente não teria força normativa para alterar uma lei complementar. Advirta-se também que as matérias reservadas às leis complementares não podem ser objeto de delegação, conforme reza o art. 68, $\$ 1^{\circ}$ da Constituição Federal.

Dos males, o menor. Assim, apesar do desconforto que a banalização da forma igualmente gera, em detrimento das opções legislativas (especialmente naquelas circunstâncias nas quais a matéria reservada contém conceitos jurídicos indeterminados), é mais prudente resguardar ao Judiciário o encargo de interpretar a vontade da Constituição, pois se os parlamentares tratarem por lei complementar de assuntos que fogem totalmente da matéria reservada, preferimos entender que eles também estariam desobedecendo ao propósito constitucional; ainda mais porque também não existe qualquer dispositivo constitucional expresso que autorize a conclusão de que o legislador possa fazer leis complementares ao bel-prazer.

\section{Posicionamento do Supremo Tribunal Federal}

Existe um mito de que o controle de constitucionalidade formal seria controle estritamente jurídico, ${ }^{14}$ isto é, que apenas conferiria ao órgão judiciário a competência de verificar se as leis foram elaboradas em conformidade com a Constituição. Nesta perspectiva, entende-se que, por não entrar na análise material ou substantiva (mas apenas formal), o controle se restringe à verificação da compa-

1+ Cf. orientação de Rui Barbosa, in. BONAVIDES, Paulo. Curso de direito constitucional. 14. ed. Sāo Paulo: Malheiros, 2004. p. 297. 
tibilidade da elaboração legislativa com as determinaçōes da Constituição acerca do processo legislativo.

Primeiramente, cumpre enfatizar que, diante de todo o exposto, a verificação do controle de constitucionalidade formal, ao menos no que concerne às leis complementares, não abarca apenas o aspecto formalístico do quorum de votação, mas principalmente se a matéria é reservada ou não à lei complementar pela Constituição, o que já significa a interferência de um elemento substancial na ponderação jurídica.

Também não se pode ignorar que a prática jurisdicional ${ }^{15}$ do controle de constitucionalidade (especialmente aquela encontrada no Supremo Tribunal Federal, seu órgão de cúpula) não se restringe à análise técnica, sendo muito comuns ponderações mais políticas ${ }^{16}$ do que propriamente jurídicas, como, por exemplo, a percepção do enorme dano que a desregulamentação da matéria impugnada de vício formal poderá causar à sociedade.

Trata-se de argumento freqüente na jurisprudência e que se baseia na questão do "menor prejuízo" ou mesmo na chamada "economia legislativa". É óbvio que, muito embora a verdadeira motivação para a manutenção dos assuntos questionados da lei seja de índole mais prática do que teórica, as cortes costumam enfatizar, para melhor justificar a decisão, os aspectos jurídicos da discussão, que recaem sobre a mencionada prevalência da dimensão material das espécies normativas.

Assim, há tempos adotou o Supremo Tribunal Federal a seguinte orientação: em vez de considerar que toda matéria ordinária presente em uma lei complementar seria inconstitucional, retirando do ordenamento assuntos que foram amplamente discutidos e que, via de regra, contaram com o apoio generalizado dos cidadãos, uma vez que seus representantes os aprovaram com um quorum de maioria absoluta, reputa-se que se trata de assunto materialmente ordinário e que, doravante, muito embora conste formalmente de uma lei complementar, poderá ser alterado por lei ordinária.

Essa foi a elaboração jurisprudencial do Ministro Moreira Alves no RE $103.639^{17}$ que, na vigência da Constituição pretérita, posicionou-se da seguinte forma:

É doutrina pacífica, em face de direito constitucional federal, que só existe lei complementar para aquelas matérias para as quais a Carta Magna Federal, expressamente, exige essa espécie de lei, o que implica dizer que

\footnotetext{
15 Cf. menciona Diego Filipe Machado em artigo denominado A natureza do controle de constitucionalidade formal e a jurisprudência do Supremo Tribunal Federal a respeito do vício formal de iniciativa e a sançāo do Poder Executivo. Disponível em: <www.sbdp.org.br/ver_monografia.php?idMono=5>. Acesso em: 24 ago. 2007.

16 Na realidade, não defendemos que haja uma diferença ontológica entre argumentos do tipo político sem relação aos argumentos de cunho jurídico.

1; In: RTJ 113/392. Cf. LUZ, Ivani Silva da. Lei complementar e lei ordinária. Disponivel em: <www. neofito.com.br/artigos/art.01/const39.htm>. Acesso em: 26 fev. 2007.
} 
os dispositivos que integram formalmente uma lei complementar, mas disciplinam matéria que não está sujeita a legislação desse tipo, conservam a natureza de dispositivos de lei ordinária, podendo, inclusive, ser alterados por legislação ordinária posterior.

\section{Divergência entre o Superior Tribunal de Justiça e o Supremo Tribunal Federal na cobrança de COFINS}

Uma das maiores disputas tributárias, com variados processos em curso no país e com diferentes decisões, envolve a discussão sobre a cobrança da Contribuição para o Financiamento da Seguridade Social (COFINS) dos escritórios de advocacia e de outras sociedades civis de prestação de serviços de profissões regulamentadas. A controvérsia iniciou-se em 1996, quando o art. 56 da Lei (ordinária) $n^{\circ} 9.430$, criada naquele ano, revogou a isenção concedida às sociedades civis de profissionais pelo art. $6^{\circ}$, II, da Lei Complementar $\mathbf{n}^{\circ} 70 / 91$.

Note-se que as contribuiçōes para a seguridade social que incidem sobre o faturamento, o lucro e a folha de salário não exigem tratamento por lei complementar, conforme se observa da leitura do art. 195, I, da Constituição Federal, sendo que este fato não é ignorado pelo Supremo Tribunal Federal.

Contudo, como a maioria do Superior Tribunal de Justiça posiciona-se a favor hierarquia da lei complementar em relaçāo à lei ordinária, esta corte acolheu inúmeras ${ }^{18}$ demandas de sociedades civis pela manutenção da isenção de COFINS e considerou que lei ordinária não poderia alterar lei complementar, editando, ademais, em 2003 , a súmula $\mathrm{n}^{\mathrm{0}} 276$, com o seguinte conteúdo: "as sociedades civis de prestação de serviços profissionais são isentas de COFINS, irrelevante o regime tributário adotado".

A União conseguiu, entretanto, levar a discussão ao Supremo Tribunal Federal, sob o argumento de que, como o conflito entre lei ordinária e lei complementar tem fundamento constitucional, somente poderia ser julgado por esta última corte, tese que foi acolhida pelo Pretório Excelso. Atualmente, o Superior Tribunal de Justiça, via de regra, não tem entrado mais na discussão da questão, restringindo-se a analisar as questōes infraconstitucionais, conforme se observa do teor de parcela do seguinte acórdão:

CONSTITUCIONAL E TRIBUTÁRIO. CONFINS. ISENÇÃO. SOCIEDADES CIVIS DE PRESTAÇĀO DE SERVIÇOS PROFISSIONAIS. INCOMPATIBILIDADE ENTRE LEI COMPLEMENTAR E LEI ORDINÁ-

\footnotetext{
18 Segundo informa a tevista Consultor Jurídico de 12 de setembro de 2007, no Superior Tribunal de Justiça há cerca de cem (100) decisōes transitadas em julgado dispensando prestadoras de serviço do pagamento da COFINS, contra as quais muito provavelmente, quando o Supremo Tribunal Federal posicionar-se definitivamente, a União entrará com rescisória.
} 
RIA. PRECEDENTES DO STF. REPETIÇÃO DO INDÉBITO. TRIBUTOS SUJEITOS A LANÇAMENTO POR HOMOLOGAÇÃO. PRAZO PRESCRICIONAL. LC 118/2005. INCONSTITUCIONALIDADE DA APLICAÇĀO RETROATIVA.

1. A controvérsia a respeito da incompatibilidade entre lei ordinária e lei complementar é de natureza constitucional, já que a invasão, por lei ordinária, da esfera de competência reservada constitucionalmente à lei complementar, acarreta a sua inconstitucionalidade, e não a ilegalidade. Precedentes do STF.

2. Assim, a discussão sobre a Lei Complementar $n^{0} 70 / 91$ ser materialmente ordinária, bem como a respeito da revogação de seu art. $6^{\circ}$, II, pela Lei no 9.430/96, tem índole constitucional, sendo vedada sua apreciação em recurso especial. ${ }^{19}$

Assim, apesar de ainda não ter concluído definitivamente a votação do assunto, o Supremo Tribunal Federal se encaminha ${ }^{20}$ rumo à declaração da regularidade da cobrança da COFINS, uma vez que já firmou posicionamento que entende que lei materialmente ordinária constante de lei complementar pode ser alterada por lei ordinária.

\section{Crítica à solução adotada pelo art. 86 da Lei Complementar no 123/05}

O atual Estatuto Nacional da Microempresa e da Empresa de Pequeno Porte, que revogou o antigo estatuto previsto na Lei no 9.841/99, foi instituído por meio de lei complementar em virtude da Reforma Tributária de 2003. Esta culminou na edição da Emenda Constitucional $n^{\circ} 42 / 03$, que acrescentou a alínea $d$ ao inciso III do art. 146 da Constituição, determinando que também seria assunto de lei complementar o estabelecimento de normas gerais em matéria de legislação tributária sobre:

definição de tratamento diferenciado e favorecido para as microempresas e para as empresas de pequeno porte, inclusive regimes especiais ou simplificados no caso do imposto previsto no art. 155, II, das contribuições previstas no art. 195, I e $\$ \$ 12$ e 13, e da contribuição a que se refere o art. 239.

Antes não se exigia que a matéria fosse objeto de lei complementar. Note-se que o art. 179 da Constituição Federal não especifica que tipo de lei definirá quais são as microempresas e as empresas de pequeno porte; refere-se, pois, apenas "às microempresas e empresas de pequeno porte, assim definidas em lei".

19 REsp 952502/SP, T1, Rel. Min. Teori Zavascki, julgamento 4.9.2007. In: DJ 4-10-2007. p. 209. 
Observa-se, todavia, que o legislador acabou por tratar de todo o regramento do novo estatuto por meio de lei complementar, isto é, disciplinou na Lei Complementar n⿳0 123/06 não só assuntos atinentes, por exemplo, aos regimes especiais ou simplificados em matéria de legislação tributária, mas também assuntos que não são objeto de reserva de lei complementar, como, por exemplo, os favorecimentos nas licitações públicas.

Parece-nos, de acordo com a transcrição de parcela das sessões realizadas na Câmara dos Deputados, ${ }^{21}$ que a sugestão de que a lei complementar enfatizasse a modificação de sua matéria residual por meio de lei ordinária foi feita pelo Deputado Miro Teixeira, que, durante a exposição do relator do projeto, Luiz Carlos Hauly, pediu o seguinte aparte, in verbis:

Miro Teixeira - Deputado Luiz Carlos Hauly, peço um esclarecimento. Na negociação, falou-se em colocar um dispositivo que permitisse que as matérias tratadas em lei ordinária que migrassem para a lei complementar, no futuro, pudessem voltar a ser tratadas em projetos de lei ordinária. Tenho dúvida sobre a eficácia disso. A partir do momento em que elas integram a lei complementar, seguramente vai-se seguir o quorum da lei complementar para qualquer alteração. Todavia, não prejudicaria deixar incluída nesse projeto que virará lei complementar essa determinação da maioria, e mais à frente se discute. Além dos outros pontos já discutidos com V. Exa., quero saber se V. Exa. acata esse também.

Luiz Carlos Hauly - Deputado Miro Teixeira, acato e digo mais: o entendimento de nossa consultoria é de que essa matéria pode ser tratada por lei ordinária, inclusive por medida provisória. Mas acato a sugestão de $V$. Exa. porque não há nenhum temor de minha parte de que a matéria não seja tratada também por lei ordinária e por medida provisória.

Miro Teixeira - Então, que a lei complementar dê esse comando em todas as matérias tratadas em lei ordinária.

Luiz Carlos Hauly - Faremos isso. Peço a V. Exa. que acrescente essa ponderação.

Independentemente do momento em que a solução para o impasse ocorreu ou de quem tenha concorrido para o inusitado deslinde incorporado no art. $86 \mathrm{da}$ Lei Geral, causa estranheza o dispositivo, pois nos dá a impressão que os legisladores pouco se importam com a reserva constitucional de matérias de lei complementar, e assumem desde já como dispositivo de lei a mencionada construção jurisprudencial, criada para "salvar" algumas leis da desconstituiçāo por motivos de economia legislativa.

Parece-nos que procuram libertar-se, sem maiores preocupações, e por meio de um "salvo-conduto" de questionável constitucionalidade, do inconveniente

21 Sessão Extraordinária 144.4.52.0 da Câmara dos Deputados, de 5.9.2006. Disponível em: <www. camara.gov.br/sileg/integras/416673.pdf >. Acesso em: 20 fev. 2007. 
que enfrentariam posteriormente pela "estabilização" gerada pelo quorum absoluto em assuntos que deveriam ter sido objeto de leis ordinárias.

Apesar de acharmos que a solução exposta pelo ex-Ministro Moreira Alves tenha sido a mais adequada, diante dos problemas envolvidos, não nos agrada o conteúdo do art. 86 da Lei Geral. Beira o descaso a admissão por parte do legislador de que "matérias tratadas nesta lei complementar que não sejam reservadas constitucionalmente a lei complementar poderão ser objeto de alteração por lei ordinária", pois a decisão da Corte Suprema nesse sentido intentou corrigir equívoco legislativo que, enfatize-se, extrapolou a margem de discricionariedade que a Constituição confere no sentido de interpretar quais são as matérias reservadas à lei complementar. $\mathrm{O}$ Poder Legislativo não pode se eximir dessa tarefa, pois mesmo que a função legislativa compreenda a inovação do ordenamento, ela tem por limite as determinaçōes da Constituição Federal.

\section{Conclusões}

Diante de todo o exposto, conclui-se que:

1. Apesar da existência incontroversa de dois critérios de diferenciação entre lei complementar e lei ordinária, isto é, o formal e o material, nas situaçōes de conflito entre as duas espécies normativas primárias, ou seja, quando assunto de lei ordinária é criado ou incluído em lei complementar, não há resolução jurisdicional apta a conciliar os dois critérios.

2. Assim, ou se opta pela prevalência do aspecto formal, a partir da invalidação dos assuntos de lei ordinária constantes de lei complementar, ou pela prevalência do aspecto material, considerando que, mesmo que determinado assunto de lei ordinária tenha sido aprovado por lei complementar, trata-se de assunto materialmente de lei ordinária que, no futuro, poderá ser alterado por lei ordinária.

3. Este último posicionamento predomina no Supremo Tribunal Federal, mas, conforme demonstrado, não foi adotado pelo Superior Tribunal de Justiça quando da cobrança da COFINS de sociedades civis com profissões regulamentadas.

4. Entendemos que a decisão que causa menos efeitos perniciosos, em virtude da inevitabilidade da opção para resolver tais situaçōes conflituosas, é aquela que enfatiza a prevalência do aspecto material, pois o aspecto formal, apesar de resguardar o valor segurança jurídica, não prima pela economia legislativa e afasta do controle jurisdicional situaçōes nas quais o legislador disciplina por meio de lei complementar matéria absolutamente alheia aos assuntos reservados. 
5. Contudo, apesar de adotarmos esse posicionamento, de prevalência do aspecto material no âmbito jurisdicional (frise-se: na solução de casos concretos), reputamos absurda a saída que o legislador encontrou no art. 86 do Estatuto da Microempresa e da Empresa de Pequeno Porte, no sentido de cristalizar em regra jurídica, isto é, "normativamente", construção jurisprudencial criada pelos tribunais para corrigir erro de técnica legislativa, pois apesar de existirem casos nos quais é difícil distinguir precisamente os limites entre assuntos de lei complementar e de lei ordinária, principalmente diante da presença no texto constitucional de conceitos indeterminados como "normas gerais", o Legislador não pode se furtar da tarefa de interpretar a Constituição em busca da mais adequada via legislativa para tramitar determinados assuntos por um "salvo-conduto" simplista como este. 